\title{
Sueños y visiones de la violencia política: Negroni, Bolaño, Gelman, Zurita
}

\author{
Dreams and Visions of Political Violence: Negroni, Bolaño, Gelman, Zurita
}

\author{
María Luisa Fischer
}

\begin{abstract}
Hunter College of The City University of New York, Department of Romance Languages,
\end{abstract} New York, NY 10065, USA. Correo electrónico: maria.fischer@hunter.cuny.edu

En el artículo se ofrece una interpretación de textos poéticos de María Negroni, Roberto Bolaño, Juan Gelman y Raúl Zurita, que elaboran la violencia política de los últimos decenios en un intento de reimaginar las subjetividades y las formas de pertenencia al país y comunidad después del desastre. En esta poesía se ofrecen los sueños, las visiones y la recreación imaginativa como modelos para la memoria que se reafirma y renueva.

Palabras clave: poesía de la postdictadura, memoria, relatos de sueños, prosa poética.

Their poems elaborate on the political violence unleashed in the past decades, in an attempt to imagine new subjectivities and ways of belonging to nation and community after disaster. These poets present dreams, visions, and imaginative recreation as models for a notion of memory as renewal and reaffirmation.

Key words: postdictatorship poetry, violence, memory, telling of dreams, poetic prose.

¿Cómo ingresa a la poesía la violencia política que tuvo lugar durante el periodo de las dictaduras militares? En los inicios de los gobiernos represivos, la expresión literaria busca ser una forma de acción y participación directa en la resistencia antidictatorial al reaccionar con urgencia al quiebre social en marcha. La elaboración pausada de la experiencia resultaba improcedente, imposible. Generar lenguajes poéticos que, desde su propia especificidad, fueran capaces de responder, recrear y reflexionar el terror estatal y sus consecuencias, tanto en las subjetividades como en las modalidades de pertenencia al país, ha sido y debe ser un proceso de largo aliento, discontinuo, sujeto a cambios, ajustes, avances y retrocesos. Fue y debe ser, además, un proceso múltiple, que admite formas diversas de respuestas a una experiencia que se transforma en su percepción y significación a través del tiempo.

Sin pretender una periodización exhaustiva ni dar cuenta de una producción poética muy amplia, la poesía que se preocupa de esta temática pasa por etapas discernibles. En un primer momento, se ensaya una poesía de registro testimonial 
y de denuncia en la que, como señala Saúl Yurkievich, "la violencia estremecedora de lo real impone un grávido predominio” (1995: 125). Inmediatamente después, establecidas las condiciones de extrema censura y autocensura, se intentan formas cifradas y elípticas que privilegian una mirada alegórica o satírica; se practica la experimentación a partir de los significantes o la interartística; se proponen caminos de ruptura con respecto a las convenciones discursivas.

Como sabemos, las periodizaciones son casi siempre problemáticas, nos recuerda Carpentier en El siglo de las luces, porque son expresiones de sucesivas épocas y periodos que pueden convivir sin arreglo a cronología ni calendario. Más aún, en poesía nunca se desechan las aproximaciones anteriores, sino que estas se acumulan y subsumen en la escritura del presente por vías inesperadas y productivas. Por eso es que, paralelamente, en exilios tanto internos como externos, junto a variantes de los polos de la denuncia y la experimentación, se desarrollan obras más acabadas, lenguajes abiertos que se aprovechan de la distancia para la elaboración artística y reflexiva.

Con estos apuntes que buscan delinear el contexto de un corpus poético amplio que persiguió responder a una realidad que lo copaba todo, exploraré una zona muy delimitada de la poesía que representa a distancia la violencia dictatorial, ya que se trata de textos escritos décadas después del término de los regímenes militares. Aunque los hechos de violencia no se dibujan con precisión en sus contornos referenciales, continúan resonando de una manera particular que me parece importante describir e interpretar. En El viaje de la noche (1994) de María Negroni, "Un paseo por la literatura” (2000) de Roberto Bolaño, País que fue será (2004) de Juan Gelman y Las ciudades de agua (2007) de Raúl Zurita, el discurso poético se confunde con el relato onírico y visionario para visualizar de nuevo las destrucciones del horror y entender su permanencia y ecos en el presente. Esta zona de la poesía de la postdictadura se vuelca a la reconstrucción del país quebrado no como noción rectora, sino que forja escenas de reconocimiento y desorientación en las cuales voces de sujetos vulnerables recuerdan pesadillas y relatan sueños para imaginar una dimensión que exorcice el dolor y reconstruya comunidades o, más modestamente, tenues espacios compartidos y, en ellos, subjetividades más libres.

El viaje de la noche de María Negroni reúne breves prosas poéticas que se ubican en espacios y tiempos diversos: Estambul, el país de Napoleón, una New Jersey tierra de nadie, Maghreb, ríos, Buenos Aires, estaciones, París, puertos y aeropuertos de seguridad estricta, sitios de la imaginación. Transcurriendo por geografías móviles y tanto por la actualidad como por pasados remotos, la voz poética narra sueños que se aparecen en la página bruscamente y sin mediaciones, exhibiendo su calidad de mundos cerrados y, a primera vista, autosuficientes. Nos encontramos con algunos personajes recurrentes que van y vienen -un amante, un bebé, el ángel Gabriel, un taxista, un tú que se invoca, la familia, un náufrago de corazón vapuleado-. En conjunto, ellos van enmarcando a una hablante que viaja y busca. Las fábulas poéticas tienen una factura precisa y evocadora y, al recorrerlas, el lector asiste a escenas que interrogan acerca de los contornos que definen a un sujeto en constante movimiento. Se trata de mensajes cifrados en los que resuenan viejas temáticas -el viaje, la más evidente- cuyo alcance se desarrolla entre la música, la mística, la metafísica y la simple sorpresa ante la variedad del mundo y la imaginación.

De acuerdo a esta descripción, podría pensarse que las prosas de Negroni de 1994 no guardan conexión alguna con las preocupaciones que he establecido más arriba. 
Sin embargo, hay un texto, "La ciudad nómade”, donde la violencia política se hace fábula compleja y, sobre todo, visión. La pregunta es cómo interpretar el fragmento en función de la densidad de un volumen hecho de material onírico, elaborado a través de referencias culturales, literarias y mitos tan lejanos que parecen no haber estado nunca próximos a la historia reciente. Incluyo a continuación el poema en prosa completo:

Como si de tanto ser abril, abril se esfumara. Y yo, esa mujer cansada, sin saber qué hacer con tanta huída, dónde esconder las armas del exilio y la astucia. Al entrar, primero a un corredor y luego a un patio cuadrado y generoso, alcanzo a ver al hombre que tal vez me enseñe a amar. Por un beso, recogería ese umbral, ese cielo más hondo donde sueñan sus labios, abrazaría mis lágrimas futuras, esta penosa vida que me avanza. Pero no me detengo, el patio hierve: unos jóvenes corren, un auto frena en seco, rugen ametralladoras, la noche clandestina, hay un algo de nupcias con fantasmas, de cita cantada. De pronto, dice una voz a mi lado: -Córrete para atrás que ahí viene la ciudad-. Veo que la ciudad se acerca y pasa por delante como si fuera un río. Una novia clara. Transcurre, de izquierda a derecha, lentamente, con su perfil de almenas y de lumbre. Alborozada, me pregunto por dónde he de cruzarla (Negroni 2000[1994]: 24).

La escena fluctúa entre un tiempo a la vez preciso e indeterminado que, de tanto ser él mismo, se va esfumando. Con ese marco y en el presente del poema, el yo del exilio retorna en más de un sentido y renueva sus lazos con el amor de un hombre de otro tiempo por el cual se han vertido lágrimas. No hay referencias exactas, pero se trasunta una historia de pérdidas que afecta a quien habla, a las que se alude con el umbral que no se cruzó, el futuro soñado no cumplido y una vida del presente transcurrida en pasividad. La violencia irrumpe a fogonazos descriptivos, con "unos jóvenes que corren, un auto que frena en seco, [...] ametralladoras, la noche clandestina”, en los que se reconocen las formas exactas de la represión en la Argentina dictatorial. Quien habla no puede más que actuar con urgencia ante una realidad que "hierve". En el relato poético, se intenta recuperar la sensación que englobaría el sentido de una escena que se rememora al reaparecer en el sueño. Su dejo, su sabor, es "un algo de nupcias con fantasmas”, que alude al tiempo y al amor idos; o "una cita cantada” que interpreto como una referencia indirecta a la delación. A continuación del quiebre de la violencia, el foco del sueño gira bruscamente hacia la visión de la ciudad, que también se figura en una comparación gestáltica, es decir, pasando como pasa un río o como lo hace una novia clara. La ciudad, lugar de origen al cual la hablante ha vuelto, se asimila al país.

En el sistema de equivalencias que constituye la visión, tal como se hace con un libro que se lee de izquierda a derecha, este se ofrece a la interpretación y al desciframiento. De este modo, el poema va construyendo, desde la paradoja de su título, la imagen de un país personal, fluyendo, al que se vuelve y, al hacerlo o, mejor aún, porque a él se ha vuelto, tal como ocurre cuando se cruza un río, se consigue pasar a otro sitio. Podemos postular que el alborozo que se nombra al final del poema proviene de la posibilidad de cambiar después de revivir y revisitar una experiencia dolorosa. En este sentido, el exilio se formula como una pérdida que ofrece otros mundos y que transforma al país en una ciudad personal que, después de la catástrofe, se ofrece a la redefinición. 
La violencia política en El viaje de la noche de Negroni se enlaza a múltiples visiones oníricas que se conectan con la historia al sumergirse en los lenguajes de la imaginación y de mitos renovados. ${ }^{1}$ El gesto de recontextualizar la memoria de la violencia para integrarla a series nuevas provoca inesperadas aperturas de la significación.

Algo paralelo tiene lugar en "Un paseo por la literatura” de Roberto Bolaño, que forma parte de Tres, un libro cuyas secciones varían entre el poema narrativo y la prosa lírica que comparten una "música autobiográfica", soterrada y sutil (2000: Contraportada). Como en las prosas poéticas de Negroni, nos encontramos con un sujeto móvil que se visualiza con distintas edades transcurriendo por lugares múltiples -Civitavecchia, el paseo marítimo de New York, el Distrito Federal, los caminos del África, la Europa del nazismo, el Hemisferio Sur, un Chile que se reconoce pero que no tiene nombre-. Como en Negroni, se practica el anacronismo -de Quincey y el hablante han sido derrotados antes de hacer la revolución- y el desplazamiento espacial -este se encuentra con Gabriela Mistral en una aldea africana-.

"Un paseo ..." se compone de 57 fragmentos numerados que comienzan con la anáfora "soñé que" seguida de un relato onírico en primera persona que tiene de protagonistas a poetas y escritores de una amplia biblioteca personal que se reelabora con vitalidad. En contraste, en los cinco fragmentos iniciales que sirven de marco, habla un nosotros que se dirige a un padre en una imprecación proferida en un tiempo ulterior a la catástrofe, cuando ese yo plural ha quedado atrapado "en la miseria de [su] sueño utópico” (Bolaño 2000: 77). El yo plural corresponde al de la generación imaginada en Los detectives salvajes, rememorada por un "veterano de las guerras floridas" (Bolaño 2004: 39). En el paisaje de desolación del poema, "mientras pasa la noche" (Bolaño 2000: 79), los relatos de sueños se ofrecen como una respuesta o "un pliegue de la realidad" (énfasis agregado, Bolaño 2000: 79) en el cual el hablante, como parte de ese nosotros generacional, ve su rostro reflejado de un modo alternativo a la pesadilla histórica heredada del padre a quien encara. ${ }^{2}$

El siguiente fragmento metapoético entrega una clave acerca del modo de operación del poema largo en su conjunto: "Soñé que un hombre volvía la vista atrás, sobre el paisaje anamórfico de los sueños, y que su mirada era dura como el acero pero igual se fragmentaba en múltiples miradas cada vez más inocentes, cada vez más desvalidas” (Bolaño 2000: 105). Con una perspectiva que mezcla lo gélido con lo vulnerable, para un sujeto que al mirar se multiplica y expande, los sueños se proponen como maneras de enfocarse en el desencanto que ya se conocía y estaba a la vista y en la memoria, para observarlo ahora desde un ángulo provocador y sorprendente. Esa es justamente la oportunidad que ofrecen las representaciones anamórficas en la

En la novela La Anunciación (2007), Negroni rememora el periodo de la guerra sucia en la Argentina a través de la voz de una sobreviviente que dialoga consigo misma y con Humboldt, un desaparecido que fue su amado de juventud. El siguiente pasaje, que corresponde al monólogo interior de la narradora en Roma, sigue de cerca las preocupaciones de la escena de El viaje de la noche: "Está claro que logré sobrevivir. Nunca me detuve a averiguar las circunstancias. Me hice la muerta por años. Así fue. Me callé y algo se calló conmigo. La multitud, la marcha, el río" (Negroni 2007: 214).

2 En el poema "Los años", recogido en La Universidad Desconocida, se concluye con la escena que se expande y elabora en el texto del 2000 que analizamos: "Un poeta latinoamericano que al llegar la noche / se echa en su jergón y sueña / Un sueño maravilloso / que atraviesa países y años / Un sueño maravilloso / que atraviesa enfermedades y ausencias” (Bolaño 2007: 402). Según Carolina López, la editora de La Universidad ..., el poema fue compuesto entre 1987 y 1994. 
pintura, al integrar visiones que violan la supremacía de una perspectiva central que regula y ordena la totalidad del campo visual. ${ }^{3}$

La revisión sutil de la historia personal y la historia a secas que se ofrece en el poema se lleva a cabo a través de los mundos de libros y lecturas, los que a su vez se entretejen e identifican con las diversas edades y lugares superpuestos por donde el sujeto ha transcurrido. Con una mirada retrospectiva sobre el ambiente cambiante y móvil de las escenas oníricas, estas se ofrecen como chispazos que iluminan un instante o circunstancia precisa de la vida que se van confundiendo con un libro recordado. El ambiente es de una violencia a veces abierta, a veces soterrada, y quien sueña está siempre en movimiento, ya sea a punto de partir o alternativamente intentando volver a casa. Dos fragmentos que se ubican frente a frente en el libro reflejan bien el alcance de esta escritura. El primero es el siguiente: "Soñé que los soñadores habían ido a la guerra florida. Nadie había regresado. En los tablones de cuarteles olvidados en las montañas alcancé a leer algunos nombres. Desde un lugar remoto una voz transmitía una y otra vez las consignas por las que ellos se habían condenado” (Bolaño 2000: 102).

Marcada por el desencanto, la crítica a las derrotas históricas de una generación que dio la vida en las luchas sociales de los años setenta, esas guerras floridas sin retorno, es feroz, como se expresa en la melancolía de consignas transmitidas desde lejos que resuenan aún en “cuarteles olvidados” y por las cuales los jóvenes soñadores sociales se condenaron. El hablante las escucha cuando vuelve a esos sitios en busca de rastros que se han ido borroneando. La contrapartida de esta visión de ruinas tiene lugar en el sueño que se entrega inmediatamente a continuación: "Soñé que volvía a los caminos, pero esta vez ya no tenía quince años sino más de cuarenta. Sólo poseía un libro, que llevaba en mi pequeña mochila. De pronto, mientras iba caminando, el libro comenzaba a arder. Amanecía y casi no pasaban coches. Mientras arrojaba la mochila chamuscada en una acequia sentí que la espalda me escocía como si tuviera alas” (Bolaño 2000: 103).

Como el personaje de Negroni, la voz que habla viaja por lugares del pasado que han sido definitorios y continúan siendo entrañables. Despojado de cargas, debe tirar el único libro que se le incendia en la mochila. Esa literatura que arde y hiere, multiforme y transformadora, es la contrapartida de la voz única del eco de las consignas repetidas desde ningún lugar que se menciona en el sueño anterior y marca a quien la lee con su quemadura o alas, símbolos de libertad. Aunque el tono es de desilusión y escepticismo, el sujeto del poema persigue tanto la propia identidad que se le escapa y recupera en las escenas sintéticas de los sueños, como alguna especie de calma, al menos la que podría ofrecer el continuo formado por la imaginación, la lectura, la memoria y los afectos. Se trata de una búsqueda utópica distinta, pero no necesariamente opuesta a la del padre a quien se impreca y desafía al inicio del poema. El impulso utópico se forja en un verso, extraño en cuanto a su formulación temporal, pero de una dicción definitiva, "[s]oñé que nadie muere la víspera" (Bolaño 2000: 104). En él se confronta el clásico memento mori en contraste con el tópico somnium, imago mortis, el sueño como modelo y/o prefiguración de la muerte, el de este verso que se niega a ser imagen del fin.

Se trata de un procedimiento cultivado por los pintores del renacimiento y barroco. El ejemplo clásico de imagen anamórfica se encuentra en Los embajadores (1533) de Hans Holbein, el Joven, en el disco ubicado entre los dos dignatarios del retrato del pintor alemán. La calavera humana que ahí se representa solo se puede descifrar si se aplica una mirada descentrada sobre el cuadro, desde el costado. 
El poema se cierra donde empieza: con una visión de George Perec de tres años a quien Bolaño le promete cuidado y consuelo ${ }^{4}$. El escritor sin infancia deja por fin de llorar y los dos regresan a una casa que no se sabe con certeza dónde se encuentra. Esa interrogante, “¿[p]ero dónde estaba nuestra casa?”, retrotrae al nosotros de los fragmentos iniciales que, como establecimos, enmarcan el material onírico en el romance familiar y en la violencia histórica. Después del horror y las derrotas, este "paseo por la literatura” ofrece una forma de encuentro que se asemeja a la conquista de una porosa y sólida casa común que comunica, con certezas y con dificultad, con el mundo.

Un vistazo a País que fue será (2004) de Juan Gelman permite enfocarse en una temática que comparte con los textos de Negroni y Bolaño. Se trata de un libro de gran calidad que reclamaría una lectura más detallada para dar cuenta de las transformaciones y el espesor de "la escritura del duelo" que caracteriza al poeta argentino, según lo establece Geneviève Fabry (2008). Pero podemos adelantar que, en esta poesía y como efecto de la reflexión ulterior acerca de la violencia política, se reformula la idea de país y de pertenencia que se realiza desde su título mismo, es decir, la noción de que en el ahora de la escritura y entre las tapas de este libro, el país que fue será.

El epígrafe de Guillaume de Poitiers refuerza la idea al plantear que "[e]l Paraíso Perdido nunca estuvo atrás / Quedó adelante”5. No se trata de una marcha atrás nostálgica ni de un irreflexivo lanzarse hacia el futuro. Por el contrario, estas formulaciones, al torcer la temporalidad, señalan una cualidad de la memoria traumática, que no se mueve hacia adelante ni progresa en forma cronológica, sino que se caracteriza por un tiempo durativo en el que el pasado transforma, altera e interrumpe el presente y que, además, se experimenta de nuevo al contarla (Whitehead 2007: 188). En efecto, en textos que fluctúan entre el verso libre y la prosa poética se le da forma literal y figurativa a la noción de un país utópico-ucrónico, el que resta o apenas se imagina después de la catástrofe.

A diferencia de Negroni y Bolaño, en País que fue será no se presentan sistemáticamente mundos oníricos, pero las imágenes complejas y densas de sus poemas breves y despojados tienen la cualidad de completitud y autonomía que reconocemos en el relato de sueños y, sobre todo, en las visiones. Los espacios privados de lo doméstico, el amor y la cotidianeidad ofrecen un remanso y son la contrapartida de la muerte y el horror de la historia que rondan al sujeto. Como sintetiza Fabry, Gelman expresa “la universalidad de una experiencia de ‘duelo esencial’ como pérdida irreparable donde lo perdido no es sustituido sino que permanece e impele a testimoniar a partir del presente que ha recobrado su espesor” (2008: 307).

Un poema que llama a reflexionar sobre la posibilidad del duelo esencial es "Buques", donde se figura el conflicto del sujeto que intenta volcarse a la densidad que le ofrece la vida del presente, imaginada como luz de otoño:

Hay un homenaje evidente a la correspondiente colección de sueños de George Perec, La boutique obscure. 124 rêves (1973). Para la relación del escritor chileno con el francés, ver Rodrigo Pinto (2012: 205-212).

Asimismo, el poema "El menos pensado" que cierra el libro, se atreve a proyectar el día ucrónico/utópico "en que el corazón aprenda a leer y a escribir”. Entonces “encontrarán / la palabra que se perdió / hace millones de dolores. Véase lo que pasa: / el día que vino y se fue / será un gran día” (Gelman 2004: 94). 
La vida espesa está ahí, ¿estoy ahí? Es ella sin condiciones y mediovive en lo evidente. Lo que aprieta el corazón no es la imagen de la mañana pintada en un cristal. Es la ingratitud de las pesadillas, todas vuelven y no dicen cómo hay que sumar lo que pasó a este fulgor de otoño que tiene caminos, luz para los buques que no viajan más (Gelman 2004: 72).

El corte del verso, que se puede describir como tan abruptamente encabalgado que se va asemejando a la prosa, subraya de manera dramática la dificultad de conciliar la pesadilla del pasado con la vitalidad del presente ante los ojos. El fulgor de la luz que ofrece caminos, transformación, movimiento -esas aperturas que perseguían y prometen los sueños vagabundos de Negroni y Bolaño- choca con la imagen de los buques detenidos o varados. Pero, además, se sugiere que la luz podría lograr iluminar los pesados navíos que aunque ya no viajen, podrían ser explorados, “dejarse viajar” aunque fuera in situ. La voz del poeta provee una visión, momentos de verdad que no se asimilan con un argumento explicatorio. En el poema, la imagen evocadora y poderosa del buque, cuya "u" resuena en algunas palabras de los versos finales, reúne pasado y presente en una relación imbricada y dinámica.

Al decir de Walter Benjamin, son las imágenes, no las narraciones o relatos, las que logran poner el entonces en relación dialéctica con el ahora, una idea que se dramatiza aún más en los textos que analizamos, al volcarse la visión o imagen en prosas poéticas (o versos que imitan su forma) que invitan a considerar y luego frustran las expectativas del relato. La visión del poeta critica nociones de progreso (o de superación u olvido) y promueve conciencia acerca de las maneras en que el pasado continúa existiendo como escándalo, como resaca, como dolor en el presente (Gubnar 2003: 7).

Una mirada somera a Las ciudades de agua de Raúl Zurita me permitirá desarrollar algunas conclusiones que intentan sistematizar lo que hemos desplegado hasta aquí. En el libro del año 2007 nos encontramos con poemas en prosa que recorren un espacio autobiográfico transformado y/o deformado por la memoria y por una imaginación onírica que lo va recreando como historia de orígenes y violencia antigua. Nos encontramos, sin duda, con un impulso más abarcador que aquel que describimos en las prosas enjoyadas de Negroni, los precisos sueños literarios de Bolaño o las visiones densas de Gelman, pero, como en ellos, se pretende reinventar la violencia del pasado enmarcándola en nuevas series que la resignifiquen. Los relatos de sueños reinventan la subjetividad de protagonistas acosados por la memoria de la violencia política. ${ }^{6}$

\footnotetext{
De hecho, en Las ciudades de agua se reescriben pasajes completos de La vida nueva (1994) y, según informa una nota autorial, formará parte de la obra titulada Zurita publicada en octubre del 2011. En el volumen de 1994 encontramos una sección dedicada a transcribir los sueños de pobladores del Campamento Silva Henríquez. En este sentido, en la obra de Zurita hay un interés constante en explorar el poder utópico del lenguaje de los sueños. Sobre el tema ver Óscar Galindo (2003: 19-29).
} 
En Las ciudades de agua, la recreación envía hacia el relato bíblico, el mito de los barqueros de la muerte, los mundos del cineasta Akira Kurosawa, la canción folklórica que canta el dolor, mientras que Negroni la transforma en leyenda, Bolaño en literatura, Gelman en visión. Por sobre todo, me parece de gran interés la elaboración de imágenes de país que desarrollan los cuatro poetas estudiados. Zurita, como sabemos, forja paisajes y geografías que están cruzados por la subjetividad del hablante y marcados de manera indeleble por los hechos de violencia que modificaron esos entornos. ${ }^{7}$ Las ciudades de agua se puede entender como un estadio en un proyecto continuo de reinvención de imágenes de país. Este se figura como visión que se despliega ante la mirada del hablante para ofrecer un espacio alternativo, algo así como un espejo líquido que va reflejando episodios de la autobiografía, los que en ocasiones se deforman hasta la alucinación:

Enteras de agua, las ciudades subían cubriendo el cielo y los millones de puntos de luz de las ventanas de sus rascacielos se espejeaban, como si fuera el mar, en la inmensa plataforma del amanecer [...]. Me acerqué a despertarla, millones de figuras de agua se iban dibujando en las ciudades suspendidas, millones de rostros de lágrimas, de bocas contraídas que se fundían unas en otras. Eran infinitos puntos de luz ondeando sobre el agua. La desperté. Su cara se reflejaba en el enorme estanque del cielo. ¿Eres tú? (Zurita 2007: 117-118).

Estas otras ciudades utópicas y ucrónicas son móviles, suben a los cielos, están cruzadas de luz, tiene una cualidad profundamente visual y se aparecen en los relatos pesadillescos con la velocidad del fragmento, como un flash visual o viñeta, con una tenue cualidad anecdótica que evoca eventos y hechos de la historia de la dictadura.

Como la ciudad que Negroni cruza como si fuera un río, se ofrece como un mecanismo para reenfocar el desencanto y recrear la pertenencia. En contraste, Bolaño inventa apenas una casa común sin lugar fijo, pero sólidamente construida por el sustento de los sueños de la literatura que cruzan fronteras y épocas. El país que fue será de Gelman existe durando en las variaciones de un duelo que no se contenta con ninguna versión apaciguada de sí.

Sabemos que establecer una memoria nacional de hechos conflictivos y traumáticos consiste siempre en un proceso complejo de supresiones y negociaciones y la historia de las transiciones chilenas y argentinas en su trato con el legado de las violaciones de los derechos humanos comprueba su radical dificultad. Además, como nos recuerda Loshitzky, identificarse con el estado-nación ha sido una de las formas más usadas para buscar legitimidad a la hora de reconstruir memoria colectiva en situaciones de post-conflicto (Cit. en Ashplant 2000: 267).

\footnotetext{
Como se sabe, los paisajes son presencias privilegiadas en la poesía de Zurita. Desde Purgatorio (1979), donde el desierto es espacio resemantizado, hasta El amor de Chile (1989), donde se intenta la refundación del país a través de la recreación de su naturaleza, su poética se sitúa en la vastedad de ambientes privilegiados -el desierto, la cordillera, los valles, los ríos- que se personifican y someten a diversas transformaciones. En el más reciente Inri (2004), los paisajes son sitial que podría prestarle una resignificación adecuada a hechos incalificables, el hecho que los cuerpos de muchos detenidos desaparecidos fueron lanzados desde el aire al mar, río y lagos del país y jamás se encontrarían. En contraste con El amor de Chile, el paisaje no se constituye como un espacio primordial y puro, cuya naturaleza consuela y apacigua. Por el contrario, queda traspasado por la presencia alteradora de los cuerpos que caen. Para este libro que considero fundamental, ver de Fischer (2010: 163-178).
} 
Por estas razones, la redefinición de las ideas de país y pertenencia que se ensaya en la poesía analizada resulta tan fundamental. Mientras la significación de un país quebrado por la violencia no se experimente y recree desde el interior, seguirá existiendo en sus andamiajes exteriores, sujetos a ritualizaciones vacías donde se van despojando de los sentidos íntimos con que marcaron la imaginación y las experiencias de los sujetos. Los poemas que he destacado avanzan en la tarea de recrear formas de pertenencia a la comunidad o al país porque integran en sus visiones y en su textualidad las marcas que la violencia ha ido dejando, extendiéndose hasta el presente en los pliegues más íntimos de las subjetividades.

\section{OBRAS CITADAS}

Fuentes primarias

Bolaño, Roberto. 2000. “Un paseo por la literatura”. Tres. Barcelona: Acantilado. 75-105. 2004. "Discurso de Caracas”. Entre paréntesis. Ensayos, artículos, discursos (19982003). Ed. Ignacio Echevarría. Barcelona: Anagrama. 31-39. . 2007. La Universidad Desconocida [poemas 1979-1994]. Barcelona: Anagrama.

Gelman, Juan. 2004. País que fue será. Madrid: Visor.

Negroni, María. 2002. Night Journey. El viaje de la noche. Trad. Anne Twitty. Princeton: Princeton UP. 1994. El viaje de la noche. Barcelona: Lumen. 2007. La Anunciación. Buenos Aires: Seix Barral.

Zurita, Raúl. Zurita. 2011. Santiago: Universidad Diego Portales. 2007. Las ciudades de agua. México: Era. . Inri. 2004. Prólogo de Alejandro Tarrab. Madrid: Visor. La vida nueva. 1994. Santiago: Universitaria. . El amor de Chile. 1989. Santiago: Los Andes. . Purgatorio. 1979. Santiago: Universitaria.

Fuentes secundarias

Fabry, Geneviéve. 2008. Las formas del vacío. La escritura del duelo en la poesía de Juan Gelman. Amsterdam-NY: Rodopi.

Fischer, María Luisa. 2010. “¿Qué puede decir la poesía sobre la memoria de la violencia política?: Inri de Raúl Zurita”. Anales de Literatura Chilena 13:163-178.

Galindo, Óscar. 2003. "Registro y transcripción testimonial en la poesía chilena actual. Lihn, Zurita”. Estudios Filológicos 38: 19-29.

Gubar, Susan. 2003. Poetry After Auschwitz. Remembering What One Never Knew. Bloomington: Indiana UP.

Loshitzky, Yosefa. 2000. "Postmemory Cinema: Second-generation Israelis Screen the Holocaust in Don't Touch My Holocaust." The Politics of War Memory and Commemoration. Eds. T. G. Ashplant, Graham Dawson y Michael Roper. Routledge: London. 182-200.

Pinto, Rodrigo. 2012. "La lista de Bolaño y Perec”. Revista UDP 9: 205-208.

Whitehead, Anne. 2007. "Trauma.” Theories of Memory. A Reader. Eds. Anne Whitehead y Michael Rossington. Baltimore: John Hopkins UP. 186-191.

Yurkievich, Saúl. 1995. "La violencia estremecedora de lo real”. Como temblor del aire. La poesía de Juan Gelman. Ensayos críticos. Ed. Lilián Uribe. Montevideo: Vintén. 125142. 
